RAD Conference Proceedings, vol. 4, pp. 55-59, 2020

ISSN 2466-4626 (online) | DOI: 10.21175/RadProc.2020.11

www.rad-proceedings.org

\title{
DOSE LOAD TO DIFFERENT PARTS OF THE BODY OF THE INTERVENTIONAL CARDIOLOGIST - FIRST RESULTS
}

\author{
Natasha Ivanova ${ }^{1 *}$, Javor Ivanov ${ }^{2}$, Bistra Manusheva $^{3}$, \\ Ismet Tahsinov4, Hrisimir Todorov ${ }^{4}$, Nikolai Aleksandrov4
}

\author{
${ }^{1}$ Medical University “Prof. Dr. Paraskev Stoyanov”, Varna, Bulgaria \\ ${ }^{2}$ S\&T Bulgaria EOOD, Sofia, Bulgaria \\ 3 Head of Radiation Protection Department, Regional Health Inspectorate, Varna, Bulgaria \\ 4Invasive Department, Cardiology Hospital, Varna, Bulgaria
}

\begin{abstract}
In this article, we present some first results of the study of the dose load on a medical team working with an angiographic X-ray system in the Department of Invasive Cardiology. In the first stage, we made measurements of the dose received by an interventional cardiologist for the most commonly used projections of the C-arm. The measurements were made at three different points of the body of the cardiologist: head, gonads and feet. The aim of this article is to determine, based on the measurements, how the dose load is distributed at different points of the body of the cardiologist when various projections of the $C$-arm of the angiographic system and at different positions of the patient's table are used. The obtained results indicate the point "Gonads" to receive the highest dose load and "Head" as the point with the lowest dose load.
\end{abstract}

Key words: G-arm type X-ray system (angiograph), dose load, cardiologist - operator, Cardiology Hospital

\section{INTRODUCTION}

The use of angiography - x-ray examination of blood vessels - began in the early 2oth century when the Portuguese physician Egas Monis of the University of Lisbon invented the technique in 1927 . Using X-rays, he was able to visualize the blood vessels of the brain with a catheter for injecting a contrast agent. [1] Two years later, in 1929, Werner Forsman became the first physician who inserted a catheter into a human heart his own. [2] In 1959, the pediatric cardiologist F. Mason Sauns (1918-1985) of the Cleveland Clinic, USA, performed the first examination of the coronary artery using a catheter, X-ray, and contrast agent. [3] In 1982, Philips developed a system that allowed realtime imaging of blood vessels in various organs by injecting the patient with a contrast agent [3].

The combination of all these steps of progress, and of course many others, leads to the modern angiographic X-ray system, intended for use in clinics and cardiology departments.

Such type of equipment is the Philips Allura Xper FD10 X-ray angiography system. [4]

The aim of our study was to evaluate, based on dosimetric measurements, the dose received at different points of the interventional cardiologist's body: "head", "gonads" and "feet". Based on the dose evaluation, the dose load in these points due to the scattered radiation had to be graded during the performed procedures with the angiographic system "Philips Allura Xper FD10".

The organs and tissue structures in the human body are differently sensitive to radiation. Therefore, specific radiation protection is recommended for some of these points during the X-ray procedures. The limbs are weakly sensitive to ionizing radiation, but the gonads are the structures most sensitive to radiation. For this reason, it is imperative to collect information about the received dose of ionizing radiation for different parts of the human body.

We focused our measurements on the three main control points of the human body: "head", "gonads" and "feet" due to the fact that they have different radiation sensitivity and are differently radiation protected during the work with an angiographic X-ray system. The analysis of the obtained results and their gradation of the dose load give us information about the reliability of the radiation protection used when performing cardiological procedures under X-ray control.

The main projections used by the medical team of the Cardiac Hospital where we did our study are the following:

Table 1. Projections for which the measurement was made

\begin{tabular}{|l|l|}
\hline LAO (Left Anterior Oblique) $\mathbf{9 0}^{\circ}$ & $\mathbf{9 0}^{\circ}$ \\
\hline LAO (Left Anterior Oblique) $30^{\circ}$ & $30^{\circ}$ \\
\hline PA (Posterior-Anteror) & $0^{\circ} / 0^{\circ}$ \\
\hline RAO - cranial (Right Anterior Oblique - cranial) & $30^{\circ} / 30^{\circ}$ \\
\hline RAO - caudal (Right Anterior Oblique - caudal) & $30^{\circ} / 15^{\circ}$ \\
\hline LAO - cranial (Left Anterior Oblique - cranial) & $30^{\circ} / 30^{\circ}$ \\
\hline LAO - caudal (Left Anterior Oblique - caudal) & $30^{\circ} / 30^{\circ}$ \\
\hline Cranial & $30^{\circ}$ \\
\hline Caudal & $30^{\circ}$ \\
\hline
\end{tabular}

*natasha i@abv.bg 


\section{METHODS}

\subsection{Dosimetric measurements}

We performed a dosimetric measurement of the dose received by a cardiologist performing an angiographic procedure. Measurements were performed for all of the 9 most commonly used C-arm projections, listed in Table 1. Each measurement was made at three points on the cardiologist's body: head, gonads and feet and for three different table positions: zero height (according to the default factory set of the system [4]), lowest possible position for the respective projection and highest possible position for the respective projection.

\section{Practical MEasurements}

The practical measurements were made in the Specialized Hospital for Active Treatment in Cardiology (SBALK) Varna, in the Department of Invasive Cardiology.

\subsection{Participants}

Participants in the dosimetric measurements:

- the first author of this article - a representative of the Medical University and processing the received data,

- service engineer maintaining the X-ray equipment: the measurements were carried out under the direct and continuous control of the service engineer of the $\mathrm{X}$-ray system,

- medical physicist - Head of the Radiation Protection Department at the Regional Health Inspectorate, Varna, working with the measuring device;

- three interventional cardiologists from the Cardiac Hospital who provided information and instructions on the interventional procedures and projections used during the measurements.

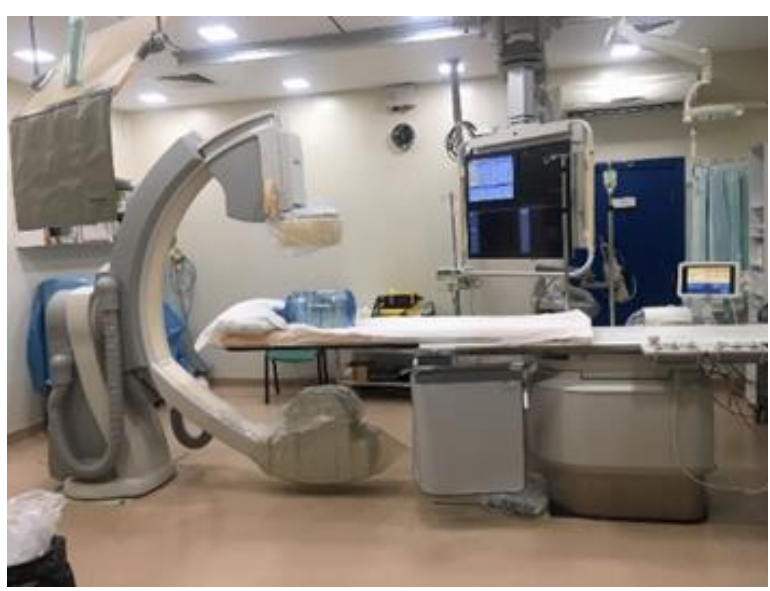

Figure 1. Angiographic X-ray system Philips Allura Xper FD10

\subsection{Devices and materials}

The study was performed in a procedure room of an angiographic X-ray system with $\mathrm{C}$-arm Philips Allura
Xper FD10 (Fig. 1). The dosimetric measurement was performed with X-Ray-Gamma-Dosimeter RGD 27091 (Fig.2) A 19-liter water bottle was used as phantom (Fig.2).

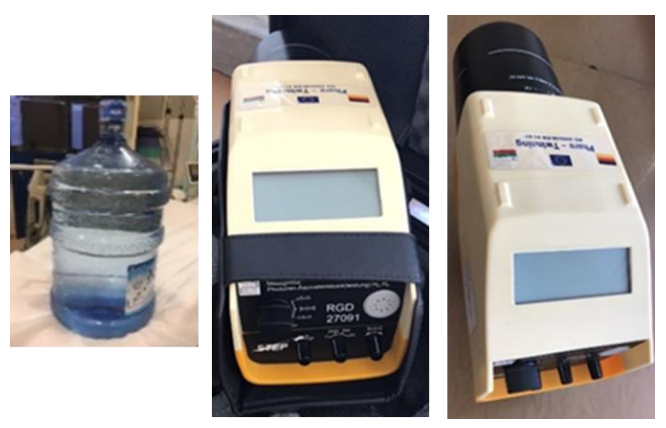

Figure 2. Phantom - a bottle of water with a volume of 19 liters (image on the left). X-Ray-Gamma-Dosimeter RGD 27091 [5]

\subsection{Procedure}

An operator who worked with the X-ray equipment and a medical physicist performing the measurements, all protected with a personal protective equipment, took part in the measurements in the interventional room. The operating mode of the equipment used was pulse fluoroscopy with parameters: $\mathrm{U}=120 \mathrm{kV}$; $\mathrm{I}=6 \mathrm{~mA}$; $\mathrm{t}=2 \mathrm{~s}$. X-ray tube is positioned under patient's table. During the measurement, only the position of the patient table changed: zero, lowest and highest position for each of the measured projections. The position of the operator in relation to the equipment and the patient table with the measured points and its distance from the radiation shield of the angiograph is shown in Fig. 3.

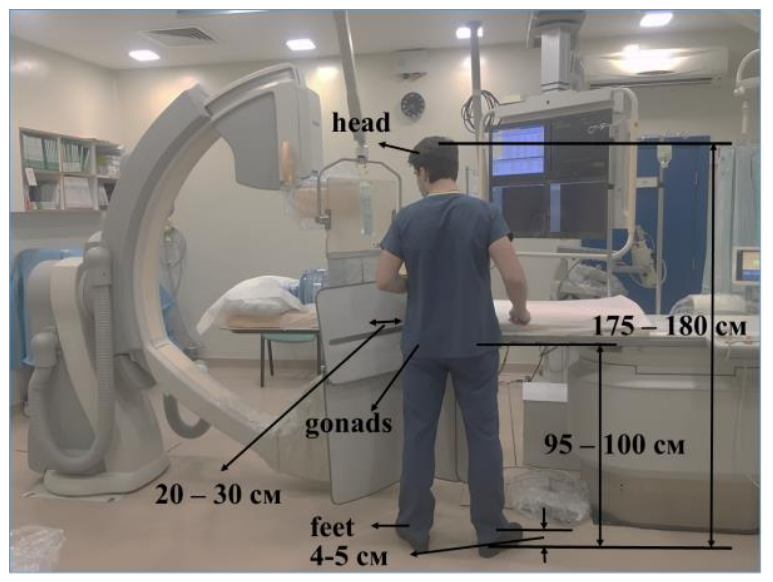

Figure 3. Position of cardiologist in relation to patient table, G-arm, radiation protection shield. Measuring points: head, gonads and steps

\section{RESULTS}

The measurements were repeated 3 to 5 times. Table 2 shows the average values from the measurements, rounded to the nearest hundredth. In Table 2 and the diagrams $(1,2,3,4)$ are presented the significant figures of the value obtained for each measurement, multiplied by $10^{-2}$. 
Table 2. Dose received by the cardiologist, measured at three points on his body, for three different positions of the patient's table

\begin{tabular}{|c|c|c|c|c|}
\hline MEASURING F & OINTS: & $\begin{array}{l}\mathbf{h} \\
\mathbf{e} \\
\mathbf{a} \\
\mathbf{d}\end{array}$ & $\begin{array}{l}\mathbf{g} \\
\mathbf{o} \\
\mathbf{n} \\
\mathbf{a} \\
\mathbf{d} \\
\mathbf{s}\end{array}$ & \\
\hline \multicolumn{2}{|c|}{ PROJECTIONS patient table position } & \multicolumn{3}{|c|}{$\begin{array}{l}\text { y.10 }{ }^{-2}, \\
\boldsymbol{\mu S v}\end{array}$} \\
\hline & lowest, $x=-9 \mathrm{~cm}$ & $\mathbf{1}$ & $\mathbf{3}$ & 2 \\
\hline \multirow[t]{2}{*}{ LAO $3^{\circ}$} & highest, $x=+13 \mathrm{~cm}$ & $\mathbf{1}$ & 5 & \\
\hline & zero, $x=0 \mathrm{~cm}$ & $\mathbf{1}$ & 3 & \\
\hline \multirow{3}{*}{ LAO 90 } & lowest, $x=-13 \mathrm{~cm}$ & $\mathbf{1}$ & 2 & \\
\hline & highest, $x=+13 \mathrm{~cm}$ & $\mathbf{1}$ & 4 & 2 \\
\hline & zero, $x=0 \mathrm{~cm}$ & $\mathbf{1}$ & 3 & \\
\hline \multirow{3}{*}{$\mathbf{P A o}^{\circ} / \mathbf{o}^{\circ}$} & lowest, $x=-13 \mathrm{~cm}$ & $\mathbf{1}$ & $\mathbf{1}$ & 1 \\
\hline & highest, $x=+13 \mathrm{~cm}$ & $\mathbf{1}$ & 2 & 3 \\
\hline & zero, $x=0 \mathrm{~cm}$ & $\mathbf{1}$ & 2 & 3 \\
\hline \multirow{3}{*}{$\begin{array}{l}\text { RAO - } \\
\text { cranial- } \\
\mathbf{3 0}^{\circ} / \mathbf{3 0}^{\circ}\end{array}$} & lowest, $x=-8 \mathrm{~cm}$ & 1 & 3 & 3 \\
\hline & highest, $x=+13 \mathrm{~cm}$ & 5 & 4 & 5 \\
\hline & zero, $x=0 \mathrm{~cm}$ & 2 & 4 & 4 \\
\hline \multirow{3}{*}{$\begin{array}{l}\text { RAO - } \\
\text { caudal- } \\
3^{\circ} / 15^{\circ}\end{array}$} & lowest, $x=-9 \mathrm{~cm}$ & $\mathbf{1}$ & 4 & $\mathbf{6}$ \\
\hline & highest, $x=+13 \mathrm{~cm}$ & 2 & 5 & 5 \\
\hline & zero, $x=0 \mathrm{~cm}$ & $\mathbf{1}$ & 3 & \\
\hline \multirow{3}{*}{$\begin{array}{l}\text { LAO - } \\
\text { cranial- } \\
\mathbf{3 0}^{\circ} / \mathbf{3 0}^{\circ}\end{array}$} & lowest, $x=-3 \mathrm{~cm}$ & 2 & 5 & 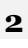 \\
\hline & highest, $x=+$ & $\mathbf{1}$ & 5 & 3 \\
\hline & zero, $x=o \mathrm{~cm}$ & $\mathbf{1}$ & 5 & 2 \\
\hline \multirow{3}{*}{$\begin{array}{l}\text { LAO - caudal- } \\
\mathbf{3 0}^{\circ} / \mathbf{3 0}^{\circ}\end{array}$} & lowest, $x=-2 \mathrm{~cm}$ & $\mathbf{1}$ & 3 & \\
\hline & highest, $x=+$ & $\mathbf{1}$ & 5 & \\
\hline & zero, $x=0 \mathrm{~cm}$ & $\mathbf{1}$ & 4 & \\
\hline \multirow{3}{*}{ Cranial- $\mathbf{3 0}^{\circ}$} & lowest, $x=-9 \mathrm{~cm}$ & $\mathbf{1}$ & 3 & \\
\hline & highest, $x=+$ & $\mathbf{1}$ & 5 & \\
\hline & zero, $x=0 \mathrm{~cm}$ & $\mathbf{1}$ & 4 & \\
\hline \multirow{3}{*}{ Caudal-3o' } & lowest, $x=-13 \mathrm{~cm}$ & 4 & 8 & \\
\hline & highest, $x=+$ & 2 & 4 & \\
\hline & zero, $x=0 \mathrm{~cm}$ & 2 & 4 & \\
\hline
\end{tabular}

Table 3 gives the values of the standard deviations for the three patient table positions at the three measured points. The minimum value of the standard deviation is 0.147 at zero table position at the measured point "head", and the maximum 0.672 - at the lowest table position at the measured point "gonads".

Table 3. Standard deviations for three position of the patient table

\begin{tabular}{|c|ccc|}
\hline & head & gonads & feet \\
\hline lowest & 0.342 & 0.672 & 0.500 \\
highest & 0.443 & 0.333 & 0.425 \\
zero & 0.147 & 0.294 & 0.373 \\
\hline
\end{tabular}

Diagram 1 shows the comparison of the data obtained from all measurements made for the different positions of the patient table, for the different projections of the angiographic system. It shows the variety in the dose values.

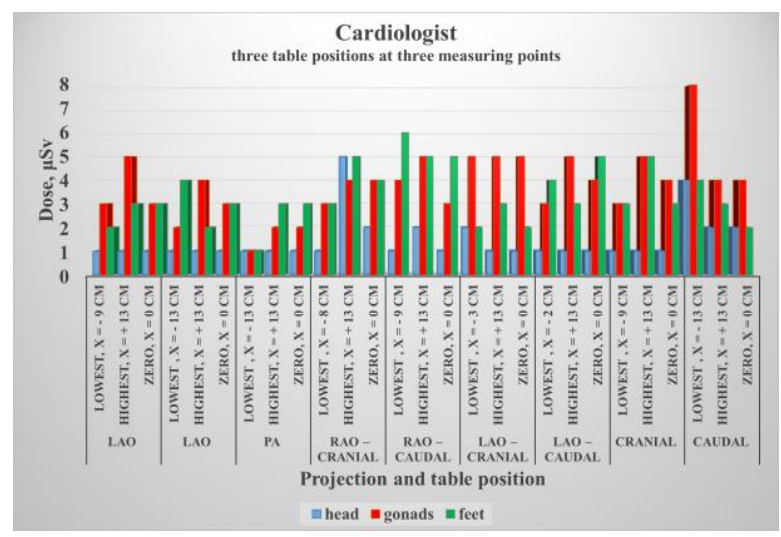

Diagram 1. Dose received by the cardiologist, measured at three points on his body, for three different positions of the patient's table

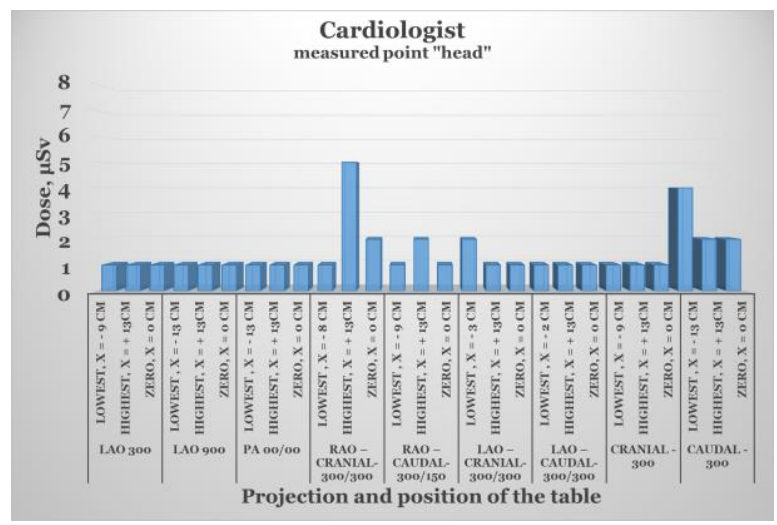

Diagram 2. Dose received by the cardiologist, for three different patient table positions, at the measurement point "Head"

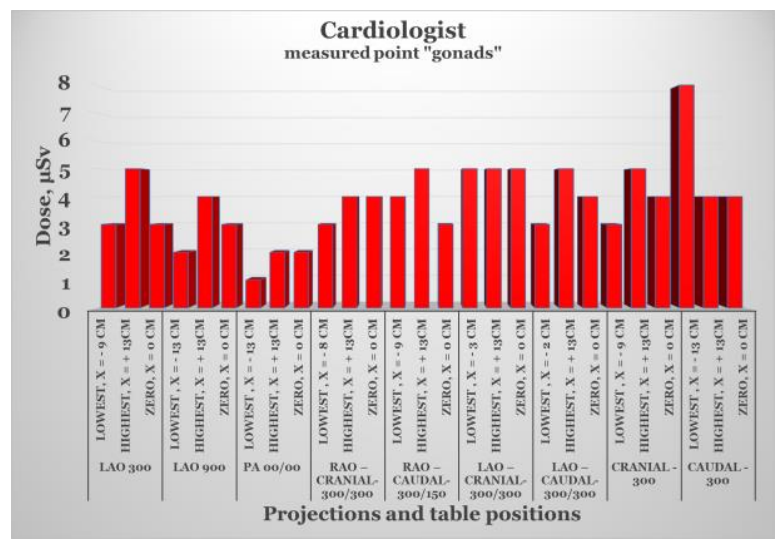

Diagram 3. Dose received by the cardiologist, for three different patient table positions, at the measurement point "Gonads"

A single maximum value of $8.10^{-2} \mu \mathrm{Sv}$ is observed only in the measurement point "Gonads" in pure Cranial projection, for the lowest position of the patient table. Again a single value of $6.10^{-2} \mu \mathrm{Sv}$ is obtained for the lowest position of the table, but for the RAO caudal projection, at the measurement point "Feet". 


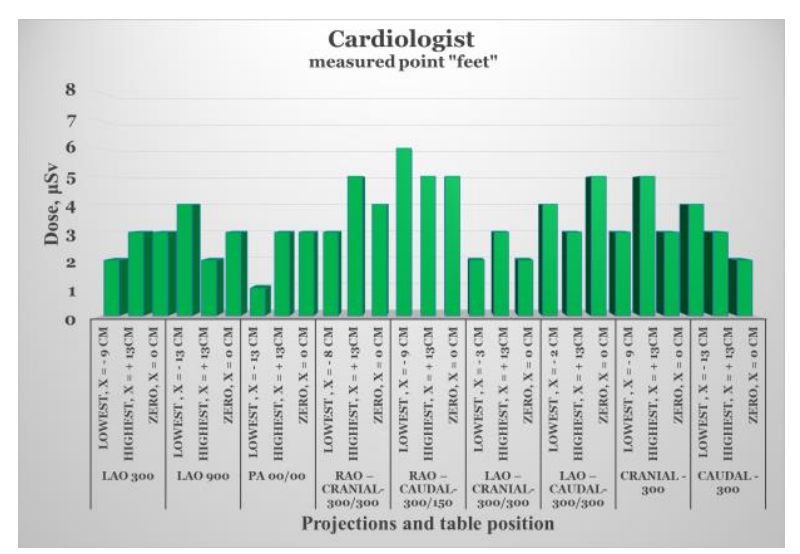

Diagram 4. Dose received by the cardiologist, for three different patient table positions, at the measurement point "Feet"

Bigger part of the projections shows one or more measured values of $5.10^{-2} \mu \mathrm{Sv}$. Most of these are at the point "Gonads" - 7 measurements, and some are measured at the point "Head" for RAO Cranial and the highest position of the patient table. In the predominant number of measurements the value of $1.10^{-2} \mu \mathrm{Sv}$ was observed - for all of the projections and most often at the point "Head" (20 measurements).

The dose load at the measurement point "Head" show lowest values. The highest value $-5 \cdot 10^{-2} \mu$ Sv, was measured in this point for RAO - cranial, when the patient table is in the highest position. For the projection pure Caudal a value of $4.10^{-2} \mu \mathrm{Sv}$ was measured and in the other 5 measurements the value of $2.10^{-2} \mu \mathrm{Sv}$ (Diagram 2).

In the obtained data for the measurement point "Gonads" the peak value is $8.10^{-2} \mu \mathrm{Sv}$ for pure Caudal and for the patient table in the lowest position (Diagram 3). In 7 measurements the values were $5.10^{-2}$ $\mu \mathrm{Sv}$, in 8 measurements the values were $4.10^{-2} \mu \mathrm{Sv}$ and in 7 measurements the values were $3.10^{-2} \mu \mathrm{Sv}$. Only in 4 measurements the values were low, namely $1.10^{-2} \mu \mathrm{Sv}$ or $2.10^{-2} \mu \mathrm{Sv}$. Only in one measurement the value was at the minimum of $1.10^{-2} \mu \mathrm{Sv}$. Diagram 3 shows the measurement at the point "Gonads", where the values are highest.

The values for the measurement point "Feet" are lower than the values for "Gonads", but still are significantly higher than for "Head". The peak value here is one, namely $6.10^{-2} \mu \mathrm{Sv}$, obtained for RAO caudal, for the lowest position of the table. There were measured 5 values each of $5.10^{-2} \mu \mathrm{Sv}$ and 4 values each of $4.10^{-2} \mu \mathrm{Sv}$. The predominant measurements showed values of $3.10^{-2} \mu \mathrm{Sv}$ - in 11 measurements. The measurements showing low values of $1.10^{-2} \mu \mathrm{Sv}$ and $2.10^{-2} \mu \mathrm{Sv}$ are 6 , where there is only one lowest value of $1.10^{-2} \mu \mathrm{Sv}$ (Diagram 4).

\section{CONCLUSION}

\subsection{Inferences}

The comparison of Diagrams 2, 3 and 4 shows maximal dose load for the measurement point "Gonads" and minimal dose load for "Head". The 58 values for the measurement point "Feet" show that here the dose load is significantly higher than for the measurement point "Head" and lower than at the point "Gonads".

The caudal projections show the highest doses and the PA-projections show lowest dose load.

Due to the fact that different angiographic procedures require the use of appropriate G-arm projections, the cardiologist cannot freely choose which projection to work with. In the process of their daily work, invasive cardiologists use all the projections discussed in the article. This means that for different invasive cardio procedures, the cardiologist will receive specific radiation dose. In the next stage of our study we will make calculations of what dose the cardiologist would receive in a specific procedure, which uses certain combination of projections.

\subsection{Recommendations}

Based on the results obtained from our study, we could make the following recommendation:

The use of appropriate individual radiation protection reduces to a safe level the dose load for the cardiologist when working with the angiographic X-ray system.

1. Due to the fact that the highest radiation dose is received at the "Gonads" point, in order to reduce the dose load at this point of cardiologist's body, it must be best protected. The gonads are one of the most radiation sensitive organs. For protection against increased radiation load, we recommend wearing a lead-rubber radiation protection apron with a minimum lead equivalent of $0.5 \mathrm{~mm}$, placed in two layers on the front of the cardiologist's body, fastened with a radiation protection belt. If a radiation protection apron with a higher lead equivalent is used, this would increase the radiation protection of the operator's body.

2. The measurement point "Head" showed the lowest values of the received dose. However, we recommend protection the cardiologist's head with a protective hat and eye protection goggles.

3. The eyes, and especially the eye lens, require special protection. In 2011, the ICRP recommended a new dose limit of $100 \mu \mathrm{Sv}$ for a period of 5 years in it publication 118. In accordance with this recommendation in the Bulgarian legislation the dose limit for ophthalmic lens was changed to $20 \mu \mathrm{Sv}$ for a period of one year and $100 \mu \mathrm{Sv}$ for a period of 5 years. For this reason, eye protection is given special attention. The radiation protection goggles contain a small amount of $210 \mathrm{~Pb}$, but when interacting with ionizing radiation, they give very good protection to the eye lens. [6] In this case, taking into account the increased attention to radiation protection of the eyes, we recommend during angiographic procedures to used goggles containing $210 \mathrm{~Pb}$. The irradiation to the eyes themselves is not high, but the procedures performed by an interventional cardiologist under $\mathrm{X}$-ray control are often more than one per day. This is a good reason to consider higher eye 
protection during invasive procedures. [7] The dose load measured at the point "Steps" is not the lowest one, but due to the fact that the feet are low-sensitivity parts of the human body, no additional protection is needed for them.

Acknowledgements: We express our great gratitude to the Specialized Hospital for Active Treatment in Cardiology, Varna and especially to its director and the staff, for the permission to conduct our study and for the invaluable help and support they provided us.

We also express our gratitude to Philips, which supported us in our research, providing us with the necessary materials and photos used in the article.

\section{REFERENCES}

1. PHILIPS, History of $X$-ray.

Retrieved from:

https://www.philips.com/consumerfiles/newscenter/mai $\mathrm{n} / \mathrm{shared} /$ assets/Downloadablefile/FACT SHEET X-

ray history.pdf

Retrieved on: Sept. 21, 2020

2. Werner Otto Theodor Forsman (in Bulg. Вернер Ото Теодор Форсман)

Retrieved from:

https://bg.pmtctdonations.org/forssmann- 5637 Retrieved on: Sept. 21, 2020

3. J.A.M. Hofman, Former Marketing Director, Universal RF Systems, Philips Healthcare, The art of medical imaging: Philips and the evolution of medical X-ray technology, Clinical applications, MEDICAMUNDI 54/1 2010.

Retrieved from:

http://incenter.medical.philips.com/doclib/enc/fetch/20 00/4504/577242/577256/588821/5050628/5313460/63 $91861 / \% 5 \mathrm{B04} \% 5 \mathrm{D}$ MM $54-$

1 Hofman.pdf\% 33 Fnodeid $=6391873$ \&vernum $=-2$

Retrieved on: Sept. 21, 2020

4. Making the difference with Philips Live Image Guidance Philips Allura Xper FD10 system specifications (C) 2017 Koninklijke Philips N.V. 4522991 18981* Apr 2017 (the article was provided by Philips)

5. Röntgen-GammaDosimeter 27091, Technical Description and Operating Instructions, September 02, 2008.

Retrieved from:

http://www.step-

sensor.de/media/main/rgd 27091 manual .pdf Retrieved on: Sept. 21, 2020

6. M. Osanai, K. Kudo, M. Hosoda, H. Tazoe, N. Akata, M. Kitajima, M. Tsushima, N. Komiya, M. Kudo, T. Tsujiguchi, M. Takagi, Y. Hosokawa, Y. Saito, "The impact on the eye lens of radiation emitted by natural radionuclides (lead-210) present in radiation protection glasses," Radiat. Prot. Dosimetry, vol. 188, no. 1, pp. 1321, Jan. 2020

https://doi.org/10.1093/rpd/ncz252

PMID: 31711199.

Retrieved from:

https://pubmed.ncbi.nlm.nih.gov/31711199/

Retrieved on: November 26, 2020

7. Y. Haga, K. Chida, Y. Kaga, M. Sota, T. Meguro, M Zuguchi "Occupational eye dose in interventional cardiology procedures,” Sci. Rep. 7, p. 569, Apr. 2017. https://doi.org/10.1038/s41598-017-00556-3 